\title{
Developing Pragmatic Competence Using EFL Textbooks: Focus on Requests
}

\author{
Anne Barron \\ Leuphana University of Lüneburg, Germany
}

\begin{abstract}
Learning to request in a foreign language is a key competence within communicative language teaching. This paper examines how requests are taught using English G2000A (Cornelsen), an EFL textbook series employed in many schools in Germany. The focus of analysis is on the linguistic request strategies and request modification (pragmalinguistics) to be learned and on the contextual information provided on the use of these linguistic forms (sociopragmatics). Findings reveal that commonly employed request strategies and cognitively simple forms of modification are introduced - also in line with developmental patterns. However, it is also found that many strategies are not dealt with and that modification is only touched on. On a sociopragmatic level, a strong focus is found to exist on standard situations in which role relations are clear. Contextual constraints are generally communicated implicitly only and there is a general danger of overgeneralization. Finally, the textbook only considers cross-cultural differences in requesting to a very narrow extent. The paper closes with some recommendations.
\end{abstract}

\section{Introduction}

Communicative language teaching, first put forward in the 1970s, remains an important approach to English language teaching today. Key to this approach is the aim that foreign language learners be empowered to use language for a range of purposes and functions and also taught to vary language use according to the participants involved and according to the particular context of use. In the foreign language context, learners are largely reliant on input from textbooks in striving to become communicatively competent. Thus, textbooks are faced with the challenge of providing input and opportunities for output in a range of areas, most prominent among them speech act realization. Previous research on textbooks has highlighted a frequent lack of representation of particular speech acts, as well as inaccurate and incomplete representations of speech acts and a paucity of metapragmatic information (cf., e.g. [1], [2], [3], [4], [5]). The present paper adds to this research, posing the question as to how requests, are taught in English
G2000A, an English as a Foreign Language (EFL) textbook published by Cornelsen, one of the main EFL publishing houses in the German context [6][11]. The presentation of and exercises on requesting in the English G2000A series are analysed from a pragmalinguistic, sociopragmatic and cross-cultural perspective in order to ascertain which request strategies and which modification are introduced and practiced and what contextual information is provided on the use of these pragmalinguistic forms. Findings are contrasted with previous findings on native speaker (NS) request realizations.

\section{Learning to request in a foreign language}

Requests are directive speech acts which represent attempts by a speaker to get the hearer to do an act $\mathrm{x}$. They are intrinsically face-threatening acts (FTAs) since in requesting, the speaker imposes on the hearer's freedom of action and, thus, threatens his/ her negative face-wants. Consequently, requests may be accomplished via indirectness and modification (cf., e.g. [12]). Conventionally indirect request strategies, such as Can you give me a lift?, for instance, create the impression that the person requested has some freedom in his/ her decision to comply with a particular request or not. Theoretically at least, he/ she could answer No, I can't (i.e. I am not able). In addition, should the person requested complain about the request for a lift, the speaker may reply that $\mathrm{s} / \mathrm{he}$ was only enquiring about the possibility of a lift (i.e. literal act: question) despite an intended requestive act. Modifiers also serve to soften a request by reducing the imposition on the hearer and lessening any negative effect associated with the illocution. By using a conditional form, such as could rather than can in our example, for instance, the speaker explicitly pays respect to the negative face of the hearer, recognizing his/ her status as an independent person.

Requests more than any other speech act have attracted researchers' attention in cross-cultural and interlanguage pragmatics. Realizing a request involves knowledge of the relevant speech act (cf. Table 1) and modification strategies. In addition, sociopragmatic knowledge is necessary for learners to know when to use which request strategy and 
which modifier(s). Such knowledge is dependent on appropriately accessing the social distance, social dominance and degree of imposition in a particular situation and knowing its effect on the realization strategy and modification employed. While many of the request strategies and modification types have been found to be largely universal, learners are faced with the challenge of acquiring the pragmalinguistic means to realize these. The relative level of difficulty of this task also depends at least partly on the existence of equivalent forms in the L1. Hassall, a cross-sectional study of Australian foreign language learners' acquisition of Bahasa Indonesian, for instance, points out that the lack of equivalence for important English modifiers, such as the politeness marker please, in Indonesian complicated acquisition [19]. With relation to sociopragmatic competence, learners' knowledge of situational variation from their first language is helpful, but cross-cultural differences on this level also exist which may lead to negative transfer. The most important differences on this level for requests in the English/ German context are detailed in the following.

House and Kasper, in a roleplay study, for instance, found a more direct locution derivable strategy (cf. Table 1) to be the preferred realization strategy in German, a contrast to the English data in which a more indirect query preparatory strategy (cf. Table 1) was favored [13]. They also found downgraders to be employed by English speakers 1.5 times as frequently as by German speakers. Within the class of downgraders, downtoners were preferred in German while hesitators were the most popular form in English. German speakers also used upgraders more than English speakers. Indeed, the latter scarcely used upgraders at all with requests [13]. Also related to these differences in modification are Ogiermann's findings on requests in English, German, Polish and Russian [14]. She reports that when modification is used, English speakers prefer consultative devices (e.g. Do you think?) (cf. also [13]), while German speakers favor downtoners (e.g. mal (eben) ['just'], vielleicht ['perhaps']) (cf. also [13]). In addition, a slightly higher use of grounders (explanations) was recorded in Ogiermann's English data [14] relative to her German data. Finally, Barron [15] found higher levels of syntactic downgrading in Irish English requests realized with query preparatory strategies relative to German NS levels (cf. also [16] for similar findings for British English and German).

Apart from such interlingual and cross-cultural differences, textbooks also need to take foreign language acquisition development patterns in requesting into account. Interlanguage pragmatic research using longitudinal and cross-sectional data elicited from foreign language learners in the foreign language context has revealed a reliance on direct request strategies in early stages of development with a gradual move to conventional indirectness. FélixBrasdefer, for example, in a cross-sectional study of three groups of adult learner requests from the beginning of foreign language instruction to advanced levels of proficiency via open role plays finds beginners to produce the largest number of direct requests [17]. By contrast, intermediate and advanced learners revealed a strong preference for conventionally indirect requests in both formal and informal situations, with a decline in direct requests noted to appear with increasing proficiency.

On the level of modification, EconomidouKogetsidis reports a preference for external modification, and in particular for the use of grounders (i.e. explanations) among learners irrespective of proficiency level [18]. In contrast, internal modification appears to increase with proficiency level (cf. [17], [18]). This is suggested to relate to the high demands which internal modification places on processing capacity. However, the levels of complexity also depend on the individual modifiers chosen (cf. [19]). Göy, Zeyrek and Otcu, for instance, in a study of Turkish EFL learners found beginners to underuse syntactic and lexical/phrasal downgraders with the exception of the cognitively simple politeness marker please ([20]). Syntactic downgrading among higher proficiency learners was restricted to conditional clauses [20]. Tense and aspect remained difficult for learners to master at that proficiency level (cf. also [21]). Such findings reflect the explanatory power of the complexification hypothesis for ILP. This hypothesis claims that certain linguistic features are acquired in line with a developmental principle. The order of development is stable and dependent on structural complexity and, therefore, on the degree of processing capacity necessary. Applied to pragmatic competence, the hypothesis predicts that learners have to first master the head act strategy of the particular speech act they wish to realise, and only then can they begin to insert modality markers. In the same vein, cognitively simple modifiers are acquired prior to complex modifiers. Thus, please generally emerges as one of the first internal modifier in requests in English (presuming the existence of L1 equivalent forms) (cf. above), while the use of more complex modifiers will gradually emerge at later stages.

Finally, availability of input and restricted learning opportunities of the linguistic means necessary for the development of request strategies and modification also plays a role. It is to findings on pragmatic input in textbooks, the main source of input in the foreign classroom context, to which we now turn. 


\section{Pragmatic input in textbooks}

Previous research on foreign and second language textbooks has focused on a range of speech acts and discourse features, including apologies ([22]), requests ([1], [22], [23], [24]), complaints/ commiserations ([4], [22]), thanking ([25]), questionanswer sequences ([3]) and closings ([2]). Such research has brought forward three main areas of criticism of textbook treatments of speech acts and discourse features. I will briefly deal with each of these in turn:

The first criticism concerns a frequent lack of representation of particular speech acts. In an analysis of closing conversations in 20 ESL textbooks by Bardovi-Harlig et al. [2], only 12 books were found to include complete closings in at least one dialogue (cf. also [5] on the number of speech acts found in an analysis of four EFL \& four ESL textbooks). Requests, however, are generally found to be plentiful in textbooks, Bardovi-Harlig [1] suggesting them to be perhaps the easiest to find of all the speech acts or conversational functions.

Textbook research has also highlighted inadequate representations of pragmatic conventions on both the pragmalinguistic and sociopragmatic levels (cf., [1], [4], [3], [25], [5]). Indeed, in a recent publication, De Pablos-Ortega for instance, suggests the need for a "more uniformed and varied representation of thanking situations" [25].

Finally, analyses have investigated the level of metapragmatic information included in textbooks. Such information may take a number of forms, including information relating to the illocutionary force of particular linguistic forms, descriptions of politeness levels (polite/ impolite), register descriptions (formal/ informal; spoken/ written) and extralinguistic contextual information. However, in general, metapragmatic information has been reported to be inadequate, particularly in an EFL context (cf. [5]).

\section{Requests in English G2000A}

The present study analyses request realizations in the German EFL textbook series English G2000, A1A6 (Cornelsen) produced for class 5-10 of the secondary school type Gymnasium [6]-[11], one of the EFL textbooks currently on offer. It addresses the following research questions:

1. Do textbooks foster pragmatic competence in requesting on a pragmalinguistic level?

2. Do textbooks foster pragmatic competence on a sociopragmatic level?

3. How accurate are textbook representations of requests on a sociopragmatic level?
4. Are developmental phases in requesting taken into account in the sequencing of request practice?

The focus of analysis was on the exercises in the textbooks focusing on requests for non-verbal goods. A total of 14 exercises were isolated in the textbook series as a whole, with a total of 18 different request structures practiced. In addition, the metapragmatic comments in the textbook were analyzed.

The coding categories employed were adopted from the Cross-Cultural Speech Act Realization Project (CCSARP), the most widely used request coding scheme to date [12]. The system functions by isolating the requestive head act and identifying the request strategy used and any modification employed.

The following coding serves as an example. The head act of the request I've just missed my bus. I was wondering if I could have a lift home? is I was wondering if I could have a lift home? Requestive head acts are realized via one of nine strategies. These are presented in Table 1. The first five strategies, from mood derivable to want statements are direct request strategies, suggestory formula and query preparatory strategies conventionally indirect strategies and the final two strategies, strong and mild hints, non-conventionally indirect strategies. In the present example, we have a conventionally indirect query preparatory strategy, questioning the possibility of being able to get a lift home. This head act strategy may be modified internally by upgrading or downgrading modifiers. Upgraders include, for instance, time intensifiers such as Open the door now, which increase the requestive force of the utterance. Mitigators, which can be lexical, phrasal or syntactic in nature, by contrast decrease the force of a particular utterance. The example above contains a combination of lexical and phrasal downgrading (subjectivizer [I wonder]) and a whole range of syntactic downgraders, namely the conditional (could)), a conditional clause (if I ...), tense ( $I$ was wondering) and aspect ( $I$ was wondering). Finally, the head-act may be surrounded by a range of external supportive moves, such as in the present example the grounder I've just missed my bus. These may be upgrading or, as in the present case, downgrading.

\section{Findings}

\subsection{Requests: A pragmalinguistic analysis}

Table 1 provides an overview of the frequency of the individual request strategies practiced in English G2000A. Figures are given as a percentage of the total number of 18 request structures dealt with in the total 14 exercises, i.e. including combinations, rather than as a percentage of the number of exercises. In 
addition, the level at which a particular strategy is introduced is also given.'

Table 1 shows that only three of the nine request strategies recognized in the request literature are dealt with in the exercises. There is no exercise on non-conventionally indirect request strategies. Those dealt with include mood derivables, locution derivables and query preparatories. Each is practiced to a broadly similar degree. Within the query preparatory category, concentration is almost exclusively on possibility questions of the form can I/ you? These strategies are those most reported on in previous research on requests. Indeed, the query preparatory strategy can almost be said to have proto-typical status among the requestive strategies in English, being employed in both standard and non-standard situations (cf., e.g. [26]) on requests in English English (EngE) and Irish English (IrE) elicited using a production questionnaire, cf. also [13]). In addition, possibility/ ability is the most frequently employed of the query preparatory types at least in EngE and IrE requests ([26]), followed by a willingness query preparatory strategy. However, interestingly, a recent corpus study of requests in British and American English [27], finds a high use of mood derivable requests to occur in conversational data. The extensive use of mood derivables in this particular study deviates from previous research - possibly due to more intimate situations in the corpus data or to the different data types. Its findings point to the importance of this direct strategy in everyday language use. With regard to locution derivables, the third main strategy focused on in the exercises in English G2000, Barron's data showed these to be used to a certain extent in standard situations.

Table 1. Frequency of request strategies in English G2000A and level of introduction

\begin{tabular}{|l|l|l|}
\hline Request strategy & Explanation & $\begin{array}{l}\text { Frequency in } \\
\text { English G2000 }\end{array}$ \\
\hline $\begin{array}{l}\text { Mood derivable } \\
\text { e.g. Move your } \\
\text { car }\end{array}$ & $\begin{array}{l}\text { Utterances in } \\
\text { which the } \\
\text { grammatical mood } \\
\text { of the verb signals } \\
\text { the illocutionary } \\
\text { force. }\end{array}$ & $\begin{array}{l}38.9 \% \\
\text { A1: }(\text { don't } \text { ) V }\end{array}$ \\
\hline $\begin{array}{l}\text { Explicit } \\
\text { performative } \\
\text { e.g. I'm asking } \\
\text { you to move your } \\
\text { car }\end{array}$ & $\begin{array}{l}\text { Utterances in } \\
\text { which the } \\
\text { illocutionary force } \\
\text { is explicitly } \\
\text { named. }\end{array}$ & - \\
\hline $\begin{array}{l}\text { Hedged } \\
\text { performative } \\
\text { e.g. I must ask } \\
\text { you to move your }\end{array}$ & $\begin{array}{l}\text { Utterances in } \\
\text { which the } \\
\text { illocutionary force } \\
\text { is named, but in }\end{array}$ & $\begin{array}{l}\text { A4: (introduced } \\
\text { in grammar part, } \\
\text { no exercise) }\end{array}$ \\
\hline \multicolumn{2}{|l}{}
\end{tabular}

\footnotetext{
${ }^{1}$ The figures given for each strategy relate to all levels at which the strategy was addressed, not just to the textbook level mentioned.
}

\begin{tabular}{|c|c|c|}
\hline car & $\begin{array}{l}\text { which it is also } \\
\text { modified by } \\
\text { hedging } \\
\text { expressions. }\end{array}$ & \\
\hline $\begin{array}{l}\text { Locution } \\
\text { derivable } \\
\text { e.g. You'll have } \\
\text { to move your car. }\end{array}$ & $\begin{array}{l}\text { Utterances in } \\
\text { which the } \\
\text { illocutionary force } \\
\text { is evident from the } \\
\text { semantic meaning } \\
\text { of the locution. }\end{array}$ & $\begin{array}{l}\text { Total: } 27.7 \% \\
\text { You mustn't } \\
\text { (16.7\%) (A1) } \\
\text { You don't need } \\
\text { to [come back] } \\
\text { (5.5\%) (A6) } \\
\text { You're not } \\
\text { allowed to } x \\
(5.5 \%)(\mathrm{A} 2)\end{array}$ \\
\hline $\begin{array}{l}\text { Want statement } \\
\text { e.g. I'd like you } \\
\text { to move your car }\end{array}$ & $\begin{array}{l}\text { Utterances which } \\
\text { state the speaker's } \\
\text { desire that the act } \\
\text { is carried out. }\end{array}$ & $\begin{array}{l}\text { A6: I'd like to } \\
\text { (introduced in } \\
\text { grammar part, } \\
\text { no exercise) }\end{array}$ \\
\hline $\begin{array}{l}\text { Suggestory } \\
\text { formula } \\
\text { e.g. How about } \\
\text { moving your car? }\end{array}$ & $\begin{array}{l}\text { Utterances which } \\
\text { contain a } \\
\text { suggestion to do } \\
\text { x. }\end{array}$ & - \\
\hline $\begin{array}{l}\text { Query } \\
\text { preparatory } \\
\text { e.g. Can you } \\
\text { move your car? }\end{array}$ & $\begin{array}{l}\text { Utterances in } \\
\text { which the } \\
\text { preparatory } \\
\text { conditions of a } \\
\text { request (e.g., } \\
\text { ability, } \\
\text { willingness, } \\
\text { possibility) are } \\
\text { addressed as } \\
\text { conventionalized } \\
\text { in any specific } \\
\text { language. }\end{array}$ & $\begin{array}{l}\text { Total: } 33.3 \% \\
\text { Can I/ you? } \\
\text { (possibility) } \\
(27.8 \% \text { ) (A1) } \\
\\
\text { Would (will) } \\
\text { you? } \\
\text { (predication) }^{2} \\
\text { (5.5\%) (A2) } \\
\text { May I? } \\
\text { (permission) } \\
\text { (A3) (no } \\
\text { exercise) }\end{array}$ \\
\hline $\begin{array}{l}\text { Strong hint } \\
\text { e.g. You've left } \\
\text { your car in a } \\
\text { dangerous place. }\end{array}$ & $\begin{array}{l}\text { Utterances } \\
\text { containing partial } \\
\text { reference to } \\
\text { objects or } \\
\text { elements needed } \\
\text { for the } \\
\text { implementation of } \\
\text { the act. }\end{array}$ & - \\
\hline $\begin{array}{l}\text { Mild hint } \\
\text { e.g. You haven't } \\
\text { seen what's } \\
\text { happened, have } \\
\text { you? }\end{array}$ & $\begin{array}{l}\text { Utterances } \\
\text { containing no } \\
\text { direct reference to } \\
\text { objects or } \\
\text { elements needed } \\
\text { for the } \\
\text { implementation of } \\
\text { the act. Instead the } \\
\text { hearer is forced to } \\
\text { interpret the } \\
\text { relevance of the } \\
\text { utterance in } \\
\text { relation to the } \\
\text { context. }\end{array}$ & - \\
\hline
\end{tabular}

House and Kasper [13] found this strategy type to be employed to a lower extent in English relative to German. Hence, based on the research mentioned,

\footnotetext{
${ }^{2}$ Will is in brackets since only would, not will is introduced. Will you? is, however, the basic predication strategy, with would you? representing the strategy with modification.
} 
we can conclude that the strategies dealt with in the textbook series at hand represent those most commonly employed at least if a native speaker norm is adopted. The fact, however, remains that the textbook does not deal with a total of six request strategies.

Moving to development issues in relation to request strategies, the analysis shows that in line with previous research, direct request strategies are addressed before indirect conventionally indirect strategies. In Table 1 we can see that the mood derivable (both positive and negative forms) is dealt with in textbook A1 [6] as well as select realizations of the locution derivable and query preparatory strategies. Concentration on the mood derivable strategy is exclusively in the low proficiency textbook, A1 [6]. Within this textbook, the mood derivable strategy is dealt with at an early stage, before either of the other strategy types. Output using the locution derivable in A1 [6] focuses exclusively on the realization of this strategy using mustn't. This is a reflection of the difficulties of transfer (cf. 5.3 below). Conceivably, a range of other direct strategies might also have been addressed in these early textbooks. The query preparatory strategy, the most commonly employed conventionally indirect strategy, is also introduced in A1 [6], but in line with the development stages, after the mood derivable. It is dealt with at approximately the same time as the locution derivable (mustn't), the latter involving also cross-linguistic differences (cf. below). Given positive transfer from German, this is a routine strategy of relative simplicity for the learner.

We turn now to syntactic downgrading. This type of internal modification is particularly important in requests in English. The conditional (could, would) is introduced in an exercise in textbook A2 [7]. Previous research has shown this form of syntactic downgrading to be employed frequently with query preparatory strategies. Barron, for instance, finds this form of modification to be the most frequently used in standard situations [26]. In non-standard situations, aspect and tense are also important, frequently used in combination in both EngE and $\mathrm{IrE}$ (cf. example above). However, in English G2000A, the conditional is the only syntactic downgrader focused on in any of the exercises from books A1 to A6 [6]-[11].

The introduction of such syntactic modification is in line with development patterns. Requests are first presented without syntactic modification. Following this, the conditional is introduced and then in line with the complexification hypothesis, the conditional clause. However, as mentioned above, more complex mitigation involving combinations of syntactic downgrading are not introduced in any of the textbooks in the series.

As far as the lexical and phrasal downgraders are concerned, only the politeness marker please is dealt with in English G2000A. It is introduced first with the direct mood derivables in A1 [6] and later in A2 [7] with the query preparatory strategy. The introduction of this politeness marker as the first lexical and phrasal downgrader is in line with development, given, in particular, equivalence in the L1 and L2 of the target population (cf. 2 above). However, although representing a "magic word" for many [15], the use of the form please underlies some pragmatic constraints which are not addressed in the textbook series. Please is namely both an illocutionary force indicating device [IFID] signaling that a particular utterance is intended as a request and also a transparent mitigator. Herein lies the difficulty because this dual function makes please predominantly suitable for use in standard situations (situations characterized by minimal imposition and clarity of rights and obligations, e.g. service encounters, passing the salt). In such circumstances, the please, functioning as an IFID, is in harmony with the formal, clearly defined, context, and so does not "drown" the downtoning qualities of the adverb (cf. [15], [26]). Consequently, please serves to mitigate the request, whether it is realized using a query preparatory or a mood derivable strategy.

In non-standard request situations, however, where query preparatory strategies are common, the function of the politeness marker as an IFID rather than as a downgrader comes to the fore. In other words, any scope for negotiation offered by the query preparatory strategy in such a situation is curtailed, and the utterance moves nearer the status of an imperative - and so becomes unfitting for a non-standard situation (cf. [15]). Consequently, use of please in non-standard situations with a query preparatory strategy represents a potential source of negative pragmatic transfer for learners [15]. However, this differentiation between the meaning of please in non-standard and standard situations is not discussed anywhere in the textbook (cf. also 5.2). Hence, overgeneralization of this, the only lexical and phrasal downgrader introduced, is possible. To illustrate that such overgeneralization is possible and indeed common in a German/English context, let me take an example of a request taken from an email between colleagues in a university context. The author of the request is a highly proficient speaker of English as a Foreign Language:

Just found this unanswered email in one of my Outlook folders. .... Since you know all the details about our future plans and needs for exchange programs, could you please formulate a few sentences? Thank you so much.

In this request, the use of the conditional could, the pre-posed grounder Since you know all the details about our future plans and needs for exchange programs and the inclusion of upgrading 
so (Thank you so much) in the closing all reflect the status of this request as a non-standard situation in which the right of the person requested to pose the request is low. Please (underlined in the present example) underlines the requestive force in such situations and is, thus, inappropriate - turning what is meant as a polite request into an order. Indeed, the inappropriateness of please in non-standard situations is shown by Barron [26] in a study of IrEng and EngE NS requests over a range of standard and non-standard situations. While please is used in the data in standard and semi-standard situations, it is not used by either the EngE or IrE speakers in nonstandard situations (cf. 5.2 for further discussion on this point).

Moving on to other modifiers, the analysis of English G2000A reveals that more complex downgraders, such as consultative devices (do you mind) or subjectivizers (I wonder, I suppose, I don't suppose, I'm afraid) are not addressed in any textbook exercise. This is particularly regrettable given the large-scale absence of these downgraders in German language use in contrast to their extensive use in English (cf. above, cf. [14], [26]).

Turning now to external modification, this modification type is neither practiced nor discussed in English G2000A. However, grounders, a common requestive supportive move, focused on giving reasons/ explanations, are included indirectly in three of the 14 exercises $(21.4 \%)$. In an exercise entitled "You mustn't watch 'Rambo 15"” [6], for instance, the requests into which pupils are required to insert the word mustn't include a grounder. An example is the utterance: You ... go into the living-room, Lulu. You're dirty. You're dirty in this case functions as a post-grounder downgrading the directive utterance. Given that as mentioned above, external modification develops early in request realizations due to low syntactic complexity, and given that grounders are commonly employed in L1 requests in German, such modification may not pose a problem to EFL learners. However, other common preparatory supportive moves in English, such as can you do me a favor?, or strategies of indebtedness (e.g. I owe you one), many of them routine in nature (cf. above, [14]), might have been dealt with in the textbook series.

\subsection{Requests: A sociopragmatic analysis}

A sociopragmatic analysis of the request representation in English G2000A shows a strong tendency towards depicting standard request situations. Metapragmatic information on the use of please with an imperative is given in the context of a grammatical explanation that the imperative form in English is the same as the infinitive form. Following this information, pupils are told "In Imperativesätzen wirf fast immer please benutzt" ("Please is nearly always used in imperative sentences' [[6]]). Such explicit information is, however, generally rare and even here this is no explicit information as to the effect of please on imperative utterances. Rather, in most instances, sociopragmatic aspects are dealt with implicitly. In an exercise entitled "Yes, please", for instance, in the A2 textbook [7], pupils are requested to "Make short dialogues with a partner. Use shall, could or would and the words in the pictures". The pictures given all depict a hotel setting in which either the customer or some of the service personnel produce a request. Here, using this information and a sample request of the form Would you come this way, please (come this way included in a picture of a concierge and a tourist), pupils are to construct requests, such as Could you call a taxi, please? or would/come you wake me at 7.00? In this exercise, the request form would/ could you $x$, please is accurately shown to be used in standard situations, such as in the service situations depicted where there is a high right to pose a request. Such information is, however, given only implicitly via reference to the context. That could you/ would you with please might be employed in such situations and not in a non-standard situation (cf. 5.1) is, however, only communicated implicitly via the context given in the picture and the propositional content of the utterances.

There are, however, also occasions in the series in which such social constraints are not communicated even implicitly (cf. also [4], [3], [1]). An exercise in textbook A2 entitled "I'm sorry" is a case in point. Here, the direction given in the exercise is to "Make up requests .... You can use the ideas in the box"; the ideas given for requests include "make the tea", "go shopping for me", "wash the dishes". This exercise communicates implicitly and inappropriately that the request form can I $x$ ? can be used without any modification in all situations regardless of the social constellations or the imposition of the request as there are no constraints on who may pose a particular request of whom and in what situation nor whether the person requesting has a right to pose the request or the person requested an obligation to comply.

\subsection{Requests: A cross-cultural analysis}

Our final focus is on the cross-cultural level. As mentioned in 2, previous findings have highlighted pragmatic differences between English and German language use. As all school-going pupils in Germany necessarily have a command of the German language, it would seem advisable to deal with such issues.

Cross-cultural pragmalinguistic differences are dealt with in English G2000A to a limited degree only. As mentioned briefly above, the contrastive interlingual differences between mustn't in English 
and nicht müssen in German are discussed within the context of the locution derivable strategy (request not to do something). Whereas mustn't in English signals that someone is forbidden from doing something and thus requested to stop (equivalent to nicht dürfen in German), the same verb nicht müssen ('mustn't') in German communicates a lack of necessity in English and is thus equivalent to needn't in English. Thus, for example, the utterance Du musst den Boden nicht wischen in German is equivalent to You needn't wash the floor in English whereas You mustn't wash the floor means you are not allowed to wash the floor and is thus a directive not to wash the floor.

Further cross-cultural differences such as, for instance, the higher use of downgrading in English requests relative to German requests or indeed crosscultural preferences for different types of downgraders (English: consultative devices, hesitators; German: downtoner) (cf. 2 above) are not dealt with.

\section{Conclusion}

Returning to our overriding question, Do textbooks foster pragmatic competence in requesting?, it has become clear that the main requesting strategies in English, the mood derivable and query preparatory strategies are dealt with in English $G 2000 A$, as well as also locution derivables. In addition, two very commonly used modifiers in English are practiced, namely the conditional and the politeness marker please. The introduction of such strategies and modification types is generally in line with development paths. However, a total of six requesting strategies in English are not introduced. Furthermore, very commonly used syntactic modification, such as the conditional clause, aspect and tense and combinations of these, are not considered. Also, lexical and phrasal downgrading is limited to the politeness marker please, a downgrader which may actually inappropriately upgrade requests in non-standard situations when combined with a query preparatory strategy. Similarly, external modification is not explicitly addressed and neither are other commonly employed external strategies, such as preparatory supportive moves or strategies of indebtedness. On the sociopragmatic level, constraints were found to be communicated implicitly and on occasion also depicted in such a way as to potentially lead to overgeneralization - and possibly to pragmatic failure. Finally, the cross-cultural analysis identified a range of desiderata on the pragmalinguistic and sociopragmatic levels which it was argued might have been addressed explicitly. Indeed, in line with current recommendations in second language instructional pragmatics (cf. [28]), not only crosscultural differences, but also pragmalinguistic and sociopragmatic issues, might be addressed explicitly rather than, as in the present textbook series, largely implicitly. We await future developments.

\section{References}

[1] K. Bardovi-Harlig, "Pragmatics and Language Teaching: Bringing Pragmatics and Pedagogy Together", in L.F. Bouton (Ed.), Pragmatics and Language Learning, University of Illinois at Urbana-Champaign, Division of English as an International Language, Urbana, IL, 1996, pp. 21-40.

[2] K. Bardovi-Harlig, B.A.S. Hartford, R. Mahan-Taylor, M.J. Morgan, and D.W. Reynolds, "Developing Pragmatic Awareness: Closing the Conversation", ELT Journal, Oxford Journals, Oxford, 1991, pp. 4-15.

[3] H. Basturkmen, "Descriptions of Spoken Language for Higher Level Learners: The Example of Questioning", ELT Journal, Oxford Journals, Oxford, 2001, pp. 4-13.

[4] D. Boxer and L. Pickering, "Problems in the Presentation of Speech Acts in ELT Materials: The Case of Complaints", ELT Journal, Oxford Journals, Oxford, 1995, pp. 44-58.

[5] H. Vellenga, "Learning Pragmatics from ESL \& EFL Textbooks: How Likely?", Teaching English as a Second or Foreign Language (TESL-EJ), 2004; http://teslej.org/ej30/a3.html (28 May 2015)

[6] English G 2000 Band A1 für das 5. Schuljahr an Gymnasien, Cornelsen, Berlin, 1996.

[7] English G 2000 Band A2 für das 6. Schuljahr an Gymnasien, Cornelsen, Berlin, 1997.

[8] English G 2000 Band A3 für das 7. Schuljahr an Gymnasien, Cornelsen, Berlin, 1999.

[9] English G 2000 Band A4 für das 8. Schuljahr an Gymnasien, Cornelsen, Berlin, 1999.

[10] English G 2000 Band A5 für das 9. Schuljahr an Gymnasien, Cornelsen, Berlin, 2001.

[11] English G 2000 Band A6 für das 10. Schuljahr an Gymnasien, Cornelsen, Berlin, 2002.

[12] S. Blum-Kulka, J. House, and G. Kasper, "The CCSARP coding manual", in S. Blum-Kulka, J. House, and G. Kasper (Eds.), Cross-Cultural Pragmatics: Requests and Apologies, Ablex, Norwood, NJ, 1989, pp. 273-294.

[13] J. House and G. Kasper, "Politeness Markers in English and German", in F. Coulmas (Ed.), Conversational Routine. Explorations in Standardized Communication Situations and Prepatterned Speech, Mouton, The Hague, 1981, pp. 157-185.

[14] E. Ogiermann, "Politeness and In-directness across Cultures: A Comparison of English, German, Polish and Russian Requests", Journal of Politeness Research, De Gruyter, Berlin/New York, 2009, pp. 189-216. 
[15] Barron, A., Acquisition in Interlanguage Pragmatics, Benjamins, Amsterdam/Philadelphia, 2003.

[16] C. Faerch and G. Kasper, "Internal and External Modification in Interlanguage Request Realization", in S. Blum-Kulka, J. House, and G. Kasper (Eds.), CrossCultural Pragmatics: Requests and Apologies, Ablex, Norwood, NJ, 1989, pp. 221-247.

[17] J.C. Félix-Brasdefer, "Pragmatic Development in the Spanish as a FL Classroom: A Cross-sectional Study of Learner Requests", Intercultural Pragmatics, De Gruyter Mouton, Berlin/New York, 2007, pp. 253-286.

[18] M. Economidou-Kogetsidis, "Modifying Oral Requests in a Foreign Language: The Case of Greek Cypriot Learners of English", in M. EconomidouKogetsidis and $\mathrm{H}$. Woodfield (Eds.). Interlanguage Request Modification, Benjamins, Amsterdam / Philadelphia, 2012, pp.163-202.

[19] T. Hassall, Requests by Australian Learners of Indonesian, Unpublished $\mathrm{PhD}$ dissertation, Australian National University, 1997.

[20] E. Göy, D. Zeyrek,and B. Otcu, "Developmental Patterns in Internal Modification Use in Requests: A Quantitative Study on Turkish Learners of English", in H. Woodfield and M. Kogetsidis (Eds.), Interlanguage Request Modification, Benjamins, Amsterdam/Philadelphia, 2012, pp. 51-87.

[21] H.P. Woodfield, "'I Think Maybe I Want to Lend the Notes from You': Development of Request Modification in Graduate Learners", in H. Woodfield and M. Kogetsidis (Eds.), Interlanguage Request Modification, Benjamins, Amsterdam/Philadelphia, 2012, pp. 9-49.

[22] E. Ogiermann, "Teaching Politeness with Green Line New?", in M. Engelhardt and W. Gehring (Eds.), Fremdsprachendidaktik. Neue Aspekte in Forschung und Lehre, Bis Verlag, Oldenburg, 2010, pp. 117-134.

[23] E. Usó-Juan, "The Presentation and Practice of the Communicative Act of Requesting in Textbooks: Focusing on Modifiers", in E. Alcón Soler and M.P. Safont Jordà (Eds.), Intercultural Language Use and Language Learning, Springer, Dordrecht, 2007, pp. 223-243.

[24] P. Salazar Campillo, "Examining Mitigation in Requests: A Focus on Transcripts in ELT Coursebooks", in E. Alcón Soler and M.P. Safont Jordà (Eds.), Intercultural Language Use and Language Learning, Springer, Dordrecht, 2007, pp. 207-222.

[25] C. De Pablos-Ortega, "The Pragmatics of Thanking Reflected in the Textbooks for Teaching Spanish as a Foreign Language", Journal of Pragmatics, Elsevier, London, 2011, pp. 2411-2433.

[26] A. Barron, "The Structure of Requests in Irish English and English English", in K.P. Schneider and A. Barron (Eds.), Variational Pragmatics: A Focus on Regional Varieties in Pluricentric Languages, Benjamins, Amsterdam/Philadelphia, 2008, pp. 35-68.
[27] I. Flöck, Requests in American and British English: A Contrastive Multi-Method Analysis, Unpublished $\mathrm{PhD}$ dissertation, University of Oldenburg, 2015.

[28] N. Taguchi, "Instructed Pragmatics at a Glance: Where Instructional Studies Were, Are, and Should Be Going. State-of-the-Art Article", Language Teaching, Cambridge University Press, Cambridge, 2015, pp. 1-50. 